\title{
ANTECEDENTES E CONSEQUENTES À SOBRECARGA DE INFORMAÇÃO EM VENDEDORES DE LOJAS FÍSICAS DE VAREJO
}

\author{
Enos Neves Coelho de Andrade* \\ enosneves@yahoo.com.br \\ Otavio Bandeira de Lamônica Freire* \\ otaviofreire@uninove.br \\ Universidade de São Paulo - SP / Brasil \\ Flavio Santino Bizzarrias* \\ flavioxsp@ hotmail.com \\ Evandro Luiz Lopes* \\ elldijo@uol.com.br \\ Universidade Federal de São Paulo - SP / Brasil \\ *Universidade Nove de Julho - SP / Brasil
}

http://dx.doi.org/10.1590/1413.2311.062.54742

Recebido em 08/04/2015

Aprovado em 27/03/2017

Disponibilizado em 31/05/2017

Avaliado pelo sistema "double blind review"

Revista Eletrônica de Administração

Editora-chefe: Andrea Oltramari

ISSN 1413-2311 (versão "on line")

Editada pela Escola de Administração da Universidade Federal do Rio Grande do Sul

Periodicidade: Quadrimestral

Sistema requerido: Adobe Acrobat Reader

\section{RESUMO}

A Sobrecarga de Informação em Vendedores é um estado vivenciado pela equipe de vendas quando está sofrendo com o grande volume de informação em suas atividades. Esse fenômeno pode ser gerador de prejuízos na atuação desses profissionais e, por consequência, no desempenho da organização como um todo. Esta pesquisa é uma nova aplicação do estudo de Hunter e Goebel (2008) a respeito da Sobrecarga de Informação em equipes de vendas, na qual foram pesquisados, como antecedentes à Sobrecarga de Informação, a Atitude Policrônica, a Sobrecarga de Papéis e a Necessidade de Cognição, e, como consequentes, a Satisfação no Trabalho e a Performance de Vendas. A relevância deste trabalho está associada à inovação feita em relação aos estudos originais, quando esta faz uso de vendedores de outro ramo de atuação (lojas físicas de varejo), e quando faz uso de uma técnica mais adequada para análise de relações causais, que é a Modelagem de Equações Estruturais. Os resultados demonstraram relação significativa e positiva entre a Sobrecarga de Papéis e a Necessidade de Cognição. Demonstraram, também, que o vendedor com maior Necessidade de Cognição pode sentir menos os efeitos da Sobrecarga de Informação, e que pode haver diminuição da Satisfação no Trabalho e da Performance de Vendas na presença de tal Sobrecarga. 
Palavras-Chave: Sobrecarga de Informação. Atitude Policrônica. Necessidade de Cognição. Sobrecarga de Papéis. Performance de Vendas no varejo. Satisfação no Trabalho.

\title{
ANTECEDENTS AND CONSEQUENCES OF INFORMATION OVERLOAD ON RETAIL SALESPERSONS
}

\begin{abstract}
Salespersons' Information Overload is a state experienced by a sales team suffering from a great volume of information in their activities. This phenomenon can affect both the professional performance of the salesperson and of the organization as a whole. This research is a new application of Hunter and Goebel's (2008) study about the impact of Salesperson Information Overload on sales people, where antecedents such as Polychronic Attitude, Role Overload and Need for Cognition, and consequences, such as Job Satisfaction and Sales Performance, were analyzed. The relevance of this work is associated with the innovation promoted in relation to the original research, as sales people from a different area of the industry (physical retail stores) were used instead. We have also applied the Structural Equation Modeling, a more appropriate technique for the analysis of causal relationships. The results demonstrated a significant positive relation between Role Overload and Need for Cognition, pointing out that a salesperson with more Need for Cognition can suffer less from the effects of Information Overload. It was also observed that Information Overload reduces both Job Satisfaction and Sales Performance.
\end{abstract}

Key words: Information Overload. Polychronic Attitude. Need for Cognition. Role Overload. Retail Sales Performance. Job Satisfaction.

\section{ANTECEDENTES Y CONSECUENCIAS A LA SOBRECARGA DE INFORMACIÓN EN VENDEDORES DE TIENDAS FÍSICAS MINORISTAS}

\section{RESUMEN}

La sobrecarga de información en vendedores es una situación experimentada por el equipo de ventas cuando está sufriendo con el gran volumen de información en sus actividades. Este fenómeno puede generar perjuicios en la actuación de estos profesionales y, consecuentemente, en el desempeño de la organización como un todo. El presente estudio es una nueva aplicación del estudio de Hunter y Goebel (2008) en el tema de la sobrecarga de información en los equipos de ventas, en el cual se estudiaron, como antecedentes a la sobrecarga de información, la actitud policrónica, la sobrecarga de papeles y la necesidad de cognición, y, como consecuencias, la satisfacción en el trabajo y el desempeño de ventas. La relevancia de este trabajo está asociada a la innovación promovida basada en los estudios originales, haciendo uso de vendedores de otro rubro de actuación (tiendas físicas minoristas) y también de una técnica más adecuada para el análisis de las relaciones causales, que es el modelado de ecuaciones estructurales. Los resultados han demostrado una relación significativa y positiva entre la sobrecarga de papeles y la necesidad de cognición. Se demostró, también, que el vendedor con mayor necesidad de cognición puede sentir menos los 
efectos de la sobrecarga de información, y que puede haber una disminución de la satisfacción en el trabajo y del desempeño de ventas en la presencia de tal sobrecarga.

Palabras clave: Sobrecarga de información. Actitud policrónica. Necesidad de cognición. Sobrecarga de papeles. Desempeño de ventas minoristas. Satisfacción en el trabajo.

\section{INTRODUÇÃO}

Esta pesquisa teve como propósito o estudo da influência da sobrecarga de informações nos vendedores no contexto do varejo (HUNTER; GOEBEL, 2008; KIM; KIM, 2012). A Sobrecarga de Informação em Vendedores é uma situação vivida pelo profissional de vendas quando é excedida sua capacidade de processamento de informações. Tal sobrecarga vivida por tais profissionais pode fazer com que estes se sintam confusos e frustrados e, consequentemente, cometam erros nas apresentações de vendas (HUNTER; GOEBEL, 2008).

A presente pesquisa teve importância porque, com a evolução dos mercados, aumentou-se em muito a quantidade de produtos disponíveis para satisfazer as necessidades dos consumidores. As exigências dos compradores também passaram a ser mais complexas, levando os vendedores a lidarem com uma infinidade de diferentes tipos de técnicas de vendas para o convencimento de interessados, aumentando assim a quantidade de informação a ser gerenciada (HUNTER; GOEBEL, 2008; HUNTER, 2004; GAUR; YAP; HAN, 2013).

Este projeto reproduziu de forma adaptada o estudo de Hunter e Goebel (2008). Utilizou o mesmo modelo teórico proposto pelos autores, contudo em um novo contexto, sendo a amostra composta por vendedores que atuam em lojas varejistas. Os vendedores utilizados como amostra atuavam em uma das maiores redes de lojas de materiais de construção do país, que funcionava com ampla variedade de produtos e grande circulação de clientes, classificadas na literatura como Homecenters (PARENTE, 2005). As características das lojas dessa rede são favoráveis a pesquisas como a proposta neste estudo, devido ao fato de haver grande volume de informações advindas dos milhares de diferentes itens comercializados, bem como dos diferentes tipos de consumidores (ANAMACO, 2013).

Foi utilizada, para mensuração dos resultados, a técnica Modelagem de Equações Estruturais (HAIR et al., 2009), com o uso da estimação dos Mínimos Quadrados Parciais PLS (Partial Least Square), com base em matriz de correlação (CHIN, 1998). Para os testes 
estatísticos, foi utilizado o software SmartPLS2.0M3 (RINGLE; WENDE, 2010; RINGLE; SILVA; BIDO, 2014).

As variáveis testadas como antecedentes à Sobrecarga de Informação foram a Atitude Policrônica, que estaria relacionada ao fato do indivíduo gostar ou não de fazer mais de uma atividade ao mesmo tempo (KAUFMAN, LANE; LINDQUIST, 1991), a Sobrecarga de Papéis (Role Overload), que teria relação com o volume de atividades advindas dos papéis que os indivíduos exercem na sociedade (REILLY, 1982; USSAHAWANITCHAKIT, 2008), e a Necessidade de Cognição, que é uma característica do indivíduo relacionada a gostar mais ou menos de pensar e de refletir sobre o porquê e sobre como funcionam as coisas (CACIOPPO; PETTY, 1984). Já as variáveis testadas como consequentes à Sobrecarga de Informação foram a Satisfação no Trabalho e a Performance de Vendas.

Este artigo está estruturado da seguinte forma: inicia-se por esta parte introdutória. $\mathrm{Na}$ seção seguinte está a revisão da literatura, contendo ainda a formulação das hipóteses de pesquisa. Em seguida, são apresentadas as seções de procedimentos metodológicos, de análise e discussão dos resultados. No final, há um fechamento com as considerações finais e com a apresentação das sugestões para pesquisas futuras e as implicações gerenciais deste trabalho.

\section{REFERENCIAL TEÓRICO}

Nesta seção, estão contidas explanações a respeito da figura do vendedor na literatura e dos construtos que serão utilizados. Ao longo da seção, estão, também, as fundamentações das relações e hipóteses a serem testadas tendo como base as teorias expostas, além da apresentação do modelo teórico.

\subsection{A figura do Vendedor}

O vendedor é o indivíduo que representa as organizações perante seus clientes. Tem como função principal vender mercadorias, mas lida também com tarefas como atuação com distribuidores, atendimento a reuniões, atendimento a serviços necessários aos produtos que vende, viagens, comunicação e informação, treinamento, dentre outras (SINGH; KOSHY, 2010). Os vendedores de loja investigados nesta pesquisa possuem algumas peculiaridades em relação ao vendedor pessoal. Atuam como funcionários da linha de frente no varejo, com alto 
contato e interação com clientes, tendo ainda que se dividir em muitas atividades além de simplesmente efetuar vendas: abastecer prateleiras, atender clientes ao telefone, organizar expositores, auxiliar nas trocas e devoluções de mercadorias, organizar a loja para os inventários, dentre outras (ARNDT; ARNOLD; LANDRY, 2006).

No ambiente de varejo, esses vendedores podem influenciar o consumidor. Segundo Kim e Kim (2012), tais profissionais compõem os fatores humanos de influência nos clientes na loja. Já para Turley e Milliman (2000), compõem o que os autores chamam de fatores sociais de influência, concorrendo com elementos como o espaço físico, as cores, a alocação das mercadorias e a organização da loja.

\subsection{A Sobrecarga de Informação e a Sobrecarga de Informação nos Vendedores}

Há um limite finito na habilidade do ser humano em assimilar e processar informações durante dada unidade de tempo. Quando esse limite é ultrapassado, o processamento tende a ser confuso e disfuncional (JACOBY; SPELLER; KOHN, 1974). Hunter (2008) atribui a Miller (1956) os primeiros estudos a respeito da sobrecarga de informação, afirmando que o processamento de informação tem a ver com o tempo para isso ser processado. Quanto menor o tempo e maior a quantidade de informação, pior a qualidade do processamento.

Miller (1956) comenta sobre entrada e saída de informação no indivíduo como um sistema de entrada e de processamento de informação. Um bom Sistema de Informação faria com que houvesse equilíbrio e correlação entre o que entra e o que sai. Se essa correlação é medida, poderá se ter uma ideia do quanto da variância de saída poderia ser atribuída à variância da entrada e do nível de flutuações aleatórias ou ruídos introduzidos pelo Sistema durante a transmissão.

O construto Sobrecarga de Informação nos Vendedores (Salespersons' Information Overload, SIO) aparece citado inicialmente na pesquisa de Hunter em 2004 (HUNTER; GOEBEL, 2008) que afirma que o grande aumento de linhas de produtos oferecidos pelas empresas trouxe mais opções para satisfação das necessidades dos clientes, e uma maior necessidade de especialização da força de vendas. Por consequência, gerou maior quantidade de informação a ser assimilada e transmitida pelos vendedores. Essa quantidade de informação teria um limite, já que seu excesso poderia ser prejudicial ao desempenho dos profissionais de vendas. 
Para Hunter (2004) e Hunter e Goebel (2008), o fenômeno Sobrecarga de Informação no Vendedor seria um construto que teria duas dimensões: a dimensão aumento de erros e a dimensão afetiva, que estaria relacionada à confusão e frustração.

Nas negociações entre vendedor e cliente, o relacionamento funciona como uma das bases, envolvendo algum tipo de manifestação e troca afetiva (DELPECHITRE 2013; GUO; NG, 2012). Além disso, os vendedores podem melhorar sua performance de vendas e aprender mais sobre seu trabalho para atender às expectativas e conquistar o reconhecimento de colegas de trabalho, clientes e supervisores (SUJAN; WEITZ; KUMAR, 1994). Como a sobrecarga de informação induziria o vendedor a cometer erros e a confundir-se devido à limitação natural da capacidade do ser humano de processamento da informação (JACOBY; SPELLER; KOHN, 1974; MILLER, 1956), isso poderia fazer com que tal profissional tivesse emoções negativas e se sentisse frustrado e confuso em seu ambiente de trabalho (HUNTER; GOEBEL, 2008).

A dimensão aumento de erros ocorreria pelo que se conhece tradicionalmente a respeito do processamento de informações nas pessoas. Com grande quantidade de opções e pouco tempo para uma tomada de decisão, as pessoas tendem a cometer erros de escolha (JACOBY; SPELLER; KOHN, 1974). Um vendedor, em meio a uma grande quantidade de opções de produtos e serviços, tendo que combinar isso com diferentes necessidades dos compradores e com diferentes técnicas de vendas, poderia cometer erros oferecendo o produto errado para o cliente errado, ou apresentar informações erradas sobre os produtos que vende (HUNTER; GOEBEL, 2008).

Outros autores estudaram os efeitos da Sobrecarga de Informação em Vendedores, como Gaur, Yap e Han (2013) que pesquisaram a relação entre comportamentos de adaptação e orientação ao cliente do Vendedor na Performance de Vendas, com mediação da Sobrecarga de Informação, e Hunter (2004) que investigou os efeitos negativos da Sobrecarga na auto eficácia do profissional e na Performance de Vendas.

\subsection{Antecedentes à Sobrecarga de Informação nos Vendedores}

Nesta seção, estão apresentados os antecedentes à Sobrecarga de Informação nos Vendedores testados nesta pesquisa, além da apresentação das referidas relações e hipóteses que nortearam a fase empírica. 
O primeiro antecedente testado foi a Atitude Policrônica, que é um traço de personalidade e está relacionada a quanto o indivíduo tende, engaja-se, gosta ou aprecia realizar mais de uma atividade ao mesmo tempo (ARNT; ARNOLD; LANDRY, 2006; SLOCOMBE; BLUEDORN, 1999). Está também relacionada ao interesse da pessoa em combinar tais atividades (LINDQUIST; KAUFMAN-SCABOROUGH, 2007; HUNTER; GOEBEL, 2008) e a quanto o indivíduo tolera ou não sofrer 'quebras' de atividades em sua rotina, como no exemplo da pessoa ter que interromper tarefas por causa de outras para terminar a anterior depois (ARNT; ARNOLD; LANDRY, 2006).

O funcionário com alta Atitude Policrônica poderia ter melhor adaptação ao trabalho na linha de frente em serviços, já que, nesse tipo de função, não existe uma agenda exata de atividades devido às imprevisíveis demandas dos clientes. Além do mais, um funcionário de loja realiza muitas tarefas, como aquelas administrativas, de reposição de mercadorias, de limpeza de prateleiras e de arranjo de displays. Em alguns momentos, precisa realizar mais de uma delas simultaneamente, ou interromper alguma por causa de outras para voltar e terminar a anterior depois. Um exemplo seria o funcionário estar repondo mercadorias e ser interrompido por um cliente para auxílio, e depois ter que voltar para terminar o que vinha fazendo anteriormente. Uma pessoa com baixa Atitude Policrônica não se sentiria bem em um ambiente assim, estando mais sujeita ao stress em suas atividades laborais. Sentiria, também, maior percepção de distribuição injusta de trabalho, com consequências em sua satisfação profissional (ARNT; ARNOLD; LANDRY, 2006).

Na relação entre Sobrecarga de Informação e Atitude Policrônica, pode-se pensar que ambas têm a ver com o uso do tempo pelo indivíduo. A Sobrecarga de Informação, por exemplo, aumenta conforme a diminuição do tempo e o aumento de informação (JACOBY; SPELLER; KOHN, 1974; MILLER, 1956; HUNTER; GOEBEL, 2008; HUNTER, 2004).

Devido à menor quantidade de tempo exigida nos processos de vendas, o vendedor que tem maior habilidade de gerenciamento do tempo é premiado. Uma forma de fazer isso seria com a combinação de atividades (HUNTER; GOEBEL, 2008). O profissional de vendas, sob efeito da Sobrecarga de Informação, sofreria com aumentos de erros nas apresentações de vendas e se sentiria frustrado, porém o que tivesse maior Atitude Policrônica estaria menos propenso a isso, porque seria mais hábil em lidar com o volume de tempo. Isso foi verificado por Hunter e Goebel (2008), contudo sem os testes terem sido feitos com vendedores de lojas físicas de varejo. Por isso, a primeira parte da primeira hipótese a ser testada nesta pesquisa é: 
H1a - A Atitude Policrônica tem relação negativa com a Sobrecarga de Informação de Informação em Vendedores de lojas físicas de Varejo.

A Necessidade de Cognição foi também um antecedente à Sobrecarga de Informação testado nesta pesquisa e refere-se à tendência do indivíduo em se engajar e apreciar esforços cognitivos. Teria a ver com o indivíduo gostar de pensar mais ou menos a respeito das coisas (CACIOPPO; PETTY, 1984).

O indivíduo com maior Necessidade de Cognição teria tendência a processar argumentações de mensagem mais ativamente, enquanto que aquele com baixa Necessidade de Cognição procuraria entender a mensagem mais perifericamente. Além do mais, uma pessoa com maior necessidade de cognição prestaria mais atenção a uma mensagem persuasiva, e teria maior desejo ou habilidade de organizar a informação contida na mensagem. Esse processamento deixaria recipientes de mensagens, influenciando em atitudes pós-mensagem (HUNT et al., 1994).

Hunter e Goebel (2008) argumentaram que a Atitude Policrônica estaria relacionada a ações que exigiriam baixo esforço cognitivo, como andar e conversar ao mesmo tempo, ou comer enquanto assiste TV. Por esse motivo, para que a Atitude Policrônica tivesse efeitos negativos nos efeitos na Sobrecarga de Informação, haveria a necessidade do indivíduo gostar muito de pensar a respeito das coisas, ou seja, de ter alta Necessidade de Cognição, porque esse indivíduo se envolveria mais em situações que o sobrecarregariam em termos de informação. Pelas razões demonstradas, a segunda parte da primeira hipótese é:

H1b - O relacionamento entre Atitude Policrônica e Sobrecarga de Informação nos Vendedores em lojas físicas de Varejo é mediado pela Necessidade de Cognição.

A Sobrecarga de Papéis (Role Overload) ocorre quando a grande quantidade de comportamentos demandados pelas posições ocupadas pela pessoa na sociedade (pai, profissional, marido, mãe, esposa, etc.) excedem seu tempo e energia disponíveis (REILLY, 1982). Para Ussahawanitchakit (2008) e Lu e Lee (2007), a Sobrecarga de Papéis (Role Overload) é definida como uma falta individual de recursos para preenchimento de diferentes papéis que necessitam de compromissos, obrigações e requerimentos.

Em um contexto de vendas, diversos são os comportamentos exigidos do profissional de vendas, como prover informações de produtos, coletar informações de clientes e lidar com 
estratégias de vendas (HUNTER; GOEBEL, 2008). O vendedor, ao ter Sobrecarga de Papéis maior, teria que lidar com grande quantidade de informação advinda dos comportamentos exigidos dele e, por isso, estaria mais susceptível aos efeitos da Sobrecarga de Informação. Pelos motivos elencados, temos a primeira parte da segunda hipótese a ser testada:

H2a -A Sobrecarga de Papéis relaciona-se positivamente com a Sobrecarga de Informação no Vendedor em vendedores de lojas físicas de varejo.

Hunter e Goebel (2008) explicam que, assim como na Atitude Policrônica, a Sobrecarga de Papéis também envolveria atividades que não demandariam grandes esforços mentais. Por isso, o relacionamento entre a Sobrecarga de Papéis e os efeitos da Sobrecarga de Informação no Vendedor poderia ser dirigido por grandes esforços mentais. Quem gosta de pensar, empregaria mais esforço mental nos comportamentos a serem desempenhados. Por isso estariam mais susceptíveis à Sobrecarga de Informação. Com tais afirmações, temos a segunda parte da segunda hipótese:

H2b - O relacionamento entre Sobrecarga de Papéis e Sobrecarga de Informação no Vendedor é mediado pela Necessidade de Cognição em vendedores de lojas físicas de varejo.

A Necessidade de Cognição, como já citado, estaria relacionada a quanto um indivíduo aprecia pensar sobre as coisas (CACIOPPO; PETTY, 1984). Na pesquisa de Hunter e Goebel (2008), foi considerado que o vendedor que tivesse essa necessidade em maior volume poderia estar mais susceptível e poderia sentir maior Sobrecarga de Informação. Nesta pesquisa, utilizamos um raciocínio diferente para formulação da hipótese: o vendedor que gosta de pensar mais poderia ter mais facilidade em lidar com muita informação, e sentiria menos o efeito da sobrecarga de informações, sendo isso o contrário do que foi elaborado por Hunter e Goebel (2008). Com isso, a terceira hipótese que foi testada nesta pesquisa está elaborada da maneira abaixo:

H3 - A Necessidade de Cognição é negativamente relacionada com a Sobrecarga de Informação nos Vendedores de lojas físicas de varejo.

\subsection{Consequentes à Sobrecarga de Informação nos Vendedores}


Nesta seção, estão apresentados os consequentes à Sobrecarga de Informação nos Vendedores testados nesta pesquisa e suas referidas relações e hipóteses.

O primeiro consequente à Sobrecarga de Informação em Vendedores testado foi a Performance de Vendas, que está relacionada à habilidade do vendedor em alcançar as quantidades e os níveis de qualidade exigidos pelas metas e objetivos de venda (HUNTER; GOEBEL, 2008; SUJAN, WEITZ; KUMAR, 1994). Também seria um comportamento avaliado em temos de sua contribuição para as metas da Organização, relacionado a um número de atividades específicas e discretas (SINGH; KOSHY, 2010). Pode ser medida tanto pelo que os vendedores produzem, que seriam as saídas de vendas, quanto pelo que eles fazem, que seriam seus comportamentos (ANDERSON; OLIVER, 1987 apud ZACOLLO; PULLINS; MALLIN, 2009).

Sujan, Weitz e Kumar (1994) afirmam que o vendedor mais efetivo teria um sistema cognitivo mais refinado de categorização das coisas do que um vendedor menos efetivo, e que é necessário que esse profissional reorganize a categorização daquilo que conhece para adaptar diferentes estratégias a diferentes situações de vendas. Segundo Hunter e Goebel (2008), numa situação de sobrecarga de informação, o vendedor se confundiria e cometeria erros, com prejuízos diretos em seu desempenho de vendas. Utilizaremos a mesma hipótese testada por Hunter e Goebel (2008), contudo em vendedores de lojas físicas de varejo. Com isso, a quarta hipótese de pesquisa é:

H4 - A Sobrecarga de Informação em Vendedores relaciona-se negativamente com a Performance de Vendas em vendedores de lojas físicas de varejo.

O outro consequente à Sobrecarga de Informação nos vendedores testado nesta pesquisa foi a Satisfação no Trabalho, que pode ser definida como um estado emocional, positivo e prazeroso, como resultado da apreciação de uma ou mais atividades relacionada à experiência passada ou presente do indivíduo com seu trabalho (LOCKE; 1976). Seria um senso geral de afeto que o empregado tem por sua situação de trabalho (ARND; ARNOLD; LANDRY, 2006), e uma medida do "quanto as pessoas gostam ou desgostam do seu trabalho" (SANTANA; CERDEIRA, 2011, p. 590).

O vendedor, ao lidar com quantidades de informação que vão além da sua capacidade de processamento, podem se frustrar e se sentir confusos. Como a Sobrecarga de Informação 
teria o efeito de diminuir emoções positivas, isso teria impacto direto na satisfação do colaborador com seu trabalho. Com isso está apresentada a quinta hipótese da pesquisa:

H5 - A Sobrecarga de Informação em Vendedores tem relacionamento negativo com a Satisfação no Trabalho em vendedores de lojas físicas de varejo.

Considerando todas as hipóteses e relações apresentadas, temos a formação do Modelo Teórico que foi testado, e que está demonstrado na figura 1:

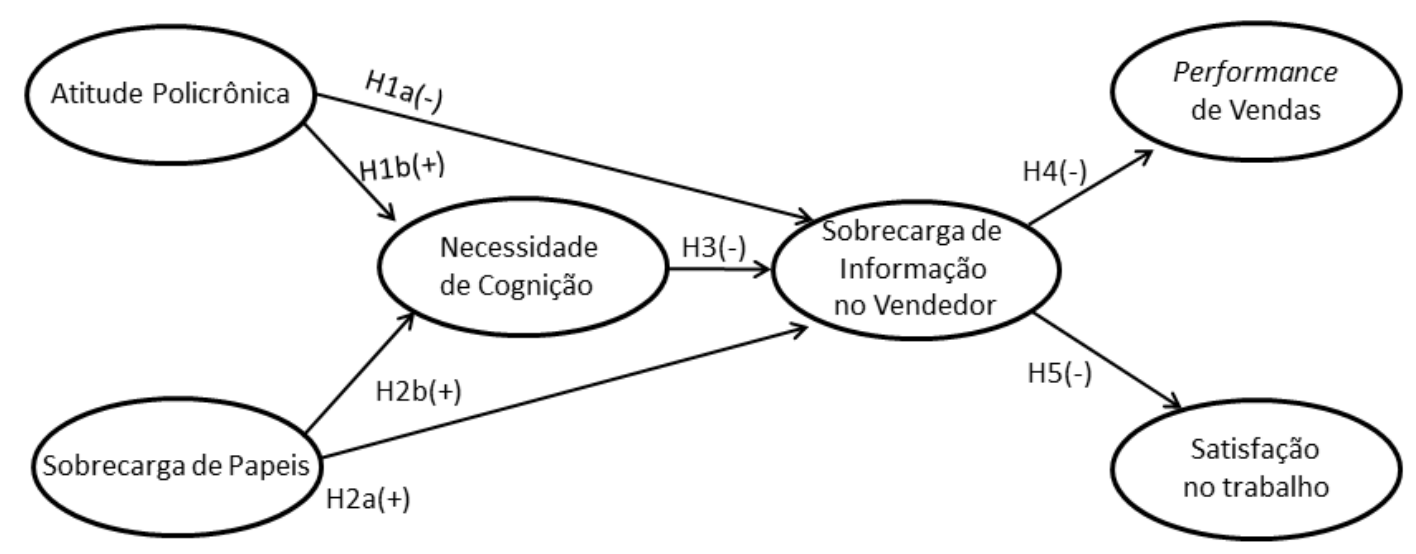

Figura 1 - Modelo teórico a ser testado na pesquisa com suas respectivas hipóteses Fonte: Adaptado de Hunter e Goebel (2008).

\section{PROCEDIMENTOS UTILIZADOS, CARACTERIZAÇÃO DA AMOSTRA E RESULTADOS}

Nesta seção, serão demonstrados os procedimentos utilizados para a pesquisa e o perfil da amostra.

\subsection{Procedimentos de coleta}

A pesquisa foi realizada com vendedores de lojas físicas de varejo de materiais de construção de uma das maiores redes do país. Tais lojas funcionam com ampla variedade de produtos e com grande circulação de clientes, e são consideradas na literatura como Homecenters (PARENTE, 2005). 
A coleta dos dados foi realizada por meio de formulários de autopreenchimento entregues aos vendedores. O preenchimento dos formulários ocorreu nas salas onde ocorrem os treinamentos dos funcionários da loja. Durante a coleta dos dados, solicitou-se que os respondentes fossem sinceros em suas considerações, pois não haveria nenhum controle que pudesse identifica-los individualmente e que todas as análises seriam realizadas com os dados agregados, garantindo assim o total sigilo prometido.

\subsection{Amostra}

Foram pesquisados 255 vendedores, contudo houve tratamento de dados perdidos (variáveis sem resposta). Seis casos foram eliminados por conterem mais de $15 \%$ de valores faltantes em determinadas variáveis, não sendo, nesses casos, recomendado tratamento (HAIR et al., 2009). Ao final do tratamento, a amostra foi reduzida a 249 casos.

Na nova amostra foram observados dados faltantes, contudo não superiores a 2,8\% por variável. Dados faltantes superiores a $5 \%$ são considerados críticos (HAIR et al., 2005). Nesses casos, os dados faltantes foram substituídos pela média da variável. Para substituição, foi também levado em conta o fato de não haver padrão nas ausências (HAIR et al., 2009).

O Quadro 1 apresenta a distribuição da amostra por faixa de renda, conforme critérios da Associação Brasileira de Empresas de Pesquisa - ABEP (2014). No Quadro 2, está a escolaridade dos respondentes, e, no Quadro 3, a distribuição por gênero:

Quadro 1 - Faixa de renda da amostra

\begin{tabular}{|c|c|}
\hline Percentual & Faixa de renda $(\mathrm{R} \$)$ \\
\hline $8,43 \%$ & $714,00-1023,00(\mathrm{D})$ \\
\hline $18,07 \%$ & $1024,00-1540,00(\mathrm{C} 2)$ \\
\hline $38,15 \%$ & $\begin{array}{c}1541,00-2564,00 \\
(\mathrm{C} 1)\end{array}$ \\
\hline $26,10 \%$ & $\begin{array}{c}2565,00-4417,00 \\
(\mathrm{~B} 2)\end{array}$ \\
\hline $7,16 \%$ & $\begin{array}{c}4418,00-8417,00 \\
(\mathrm{~B} 1)\end{array}$ \\
\hline $2,09 \%$ & Não responderam \\
\hline \multicolumn{2}{|c|}{ Fonte: Dados da pesquisa }
\end{tabular}

Quadro 2 - Escolaridade dos respondentes

\begin{tabular}{|c|c|}
\hline Percentual & Escolaridade \\
\hline $4,82 \%$ & $\begin{array}{c}\text { Ensino Fundamental } \\
\text { Completo }\end{array}$ \\
\hline
\end{tabular}




\begin{tabular}{|c|c|}
\hline $41,37 \%$ & Ensino Médio Incompleto \\
\hline $22,89 \%$ & Ensino Médio Completo \\
\hline $18,07 \%$ & $\begin{array}{c}\text { Ensino Superior } \\
\text { Incompleto }\end{array}$ \\
\hline $8,03 \%$ & $\begin{array}{c}\text { Ensino Superior } \\
\text { Completo }\end{array}$ \\
\hline $1,61 \%$ & Não responderam \\
\hline
\end{tabular}

Fonte: Dados da pesquisa

Quadro 3 - Gênero dos respondentes

\begin{tabular}{|c|c|}
\hline Percentual & Gênero \\
\hline $40,16 \%$ & Feminino \\
\hline $58,63 \%$ & Masculino \\
\hline $1,20 \%$ & Não responderam \\
\hline
\end{tabular}

Fonte: Dados da pesquisa

Em relação à idade dos respondentes, 186 responderam esse quesito. A média de idade daqueles que responderam foi de 35,14 anos ( $d p=8,53$, máxima 67 e mínima 20).

\subsection{Resultados}

Foi feita também a verificação da normalidade dos dados por meio do teste Kolmogorov Smirnov, adequado para amostras acima de 30 casos (Hair et al, 2005). Praticamente todos os itens apresentaram distribuição não aderente à curva normal teórica $(\mathrm{p}<0,05)$. A ausência de normalidade indicou que a estimação dos Mínimos Quadrados Parciais (PLS), com base em matriz de correlação, e com utilização do software Smart PLS 2.0 M3 (CHIN, 1998; RINGLE; WENDE, 2010; RINGLE; SILVA; BIDO, 2014), foi a mais adequada para a análise de dados.

De acordo com Ringle, Silva e Bido (2014), no uso da técnica PLS, primeiramente deve-se observar os modelos de mensuração, e, após, avaliar o modelo de caminhos. Na observação dos modelos de mensuração, deve-se observar a Validade Convergente obtida pela observação das Variâncias Médias Extraídas (Average Variance Extracted, AVE). Inicialmente a validade convergente não foi observada. Por isso foram eliminados 4 itens com carga inferior a 0,7 no modelo para um melhor ajuste. Os itens eliminados estão indicados no Apêndice A.

Após os procedimentos iniciais, o modelo testado apresentou Variâncias Médias Extraídas (AVE's) superiores ao mínimo exigido (AVE $>0,5)$, e indicadores de Alpha de Cronbach (entre 0,7 e 0,9), confiabilidade composta (entre 0,6 e 0,7) e comunalidade 
adequados, além de GoF (Goodness of fit, ou qualidade do ajuste) satisfatórios. O cálculo do GoF, proposto por Tenenhaus et al. (2010), por meio da média geométrica entre os valores médios dos coeficientes de determinação $\left(\mathrm{R}^{2}\right)$ e a AVE média, ficou em 0,407, acima da recomendação mínima de 0,36 para ciências sociais (WETZELS, 2009).

Tabela 1 - Indicadores de ajuste, validade convergente e confiabilidade

\begin{tabular}{|c|c|c|c|c|c|c|}
\hline Construtos & AVE & $\begin{array}{c}\text { Confiabilidade } \\
\text { composta }\end{array}$ & $\mathbf{R}^{2}$ & $\begin{array}{c}\text { Alpha de } \\
\text { Cronbach }\end{array}$ & Comunalidade & Redundância \\
\hline $\begin{array}{c}\text { Atitude } \\
\text { Policrônica }\end{array}$ & 0,698 & 0,942 & - & 0,932 & 0,698 & 0,000 \\
\hline $\begin{array}{c}\text { Necessidade } \\
\text { de Cognição }\end{array}$ & 0,607 & 0,963 & 0,061 & 0,959 & 0,607 & $-0,006$ \\
\hline $\begin{array}{c}\text { Performance } \\
\text { de Vendas }\end{array}$ & 0,808 & 0,974 & 0,030 & 0,971 & 0,808 & 0,022 \\
\hline $\begin{array}{c}\text { Satisfação no no } \\
\text { Trabalho }\end{array}$ & 0,680 & 0,965 & 0,060 & 0,962 & 0,680 & 0,032 \\
\hline $\begin{array}{c}\text { Sobrecarga } \\
\text { de } \\
\text { Informação } \\
\text { nos }\end{array}$ & 0,794 & 0,959 & 0,305 & 0,948 & 0,794 & $-0,016$ \\
Vendedores & 0,682 & 0,965 & - & 0,960 & 0,682 & 0,000 \\
\hline $\begin{array}{c}\text { Sobrecarga } \\
\text { de Papéis }\end{array}$ & 0,6 & & & \\
\hline
\end{tabular}

* $\mathrm{GoF}=0,407$ média das AVEs=0,691 Média $\mathrm{R}^{2}=0,113$

Fonte: Dados da pesquisa

Foi feita a verificação dos indicadores de Validade Discriminante do modelo estrutural, utilizando a comparação da raiz quadrada das AVEs de cada construto versus sua correlação com os demais construtos, segundo os critérios de Fornell e Larcker (1981), e como critério de avaliação, a condição das raízes quadradas das AVEs serem maiores que as correlações entre os construtos. A Validade Discriminante também foi feita de maneira complementar por meio das cargas cruzadas dos itens dos construtos versus os demais construtos (crossloadings), verificando se as variáveis indicadoras de um construto teriam carga fatorial maior em seu construto do que em outros, conforme os critérios de Chin (1998). Nesta avaliação, o item 14 da Satisfação no Trabalho foi eliminado por apresentar alta carga também no construto Performance de Vendas. A escolha dos critérios de validade discriminante seguiu as recomendações de Ringle, Silva e Bido (2014). 
A Tabela 2 demonstra os resultados da análise discriminante nos dois critérios. Já na Tabela 3 estão indicadores de acurácia $\left(\mathrm{Q}^{2}\right)$ e utilidade do construto no modelo $\left(\mathrm{f}^{2}\right)$. A Tabela 4 apresenta os resultados do modelo estrutural.

Tabela 2 - Indicadores de validade discriminante

\begin{tabular}{|c|c|c|c|c|c|c|}
\hline Construto & $\begin{array}{c}\text { Atitude } \\
\text { Policrônica }\end{array}$ & $\begin{array}{l}\text { Necessidade } \\
\text { de Cognição }\end{array}$ & $\begin{array}{l}\text { Performance } \\
\text { de Vendas }\end{array}$ & $\begin{array}{c}\text { Satisfação } \\
\text { no } \\
\text { Trabalho }\end{array}$ & $\begin{array}{c}\text { Sobrecarga } \\
\text { de } \\
\text { Informação } \\
\text { do Vendedor }\end{array}$ & $\begin{array}{c}\text { Sobrecarga } \\
\text { de Papéis }\end{array}$ \\
\hline $\begin{array}{c}\text { Atitude } \\
\text { Policrônica }\end{array}$ & $\mathbf{0 , 8 3 5}$ & & & & & \\
\hline $\begin{array}{l}\text { Necessidade } \\
\text { de Cognição }\end{array}$ & $-0,048$ & 0,779 & & & & \\
\hline $\begin{array}{c}\text { Performance } \\
\text { de Vendas }\end{array}$ & 0,042 & 0,468 & 0,899 & & & \\
\hline $\begin{array}{c}\text { Satisfação } \\
\text { no Trabalho }\end{array}$ & 0,052 & 0,430 & 0,669 & 0,825 & & \\
\hline $\begin{array}{c}\text { Sobrecarga } \\
\text { de } \\
\text { Informação } \\
\text { do Vendedor }\end{array}$ & 0,156 & $-0,223$ & $-0,172$ & $-0,245$ & 0,891 & \\
\hline $\begin{array}{c}\text { Sobrecarga } \\
\text { de Papéis }\end{array}$ & 0,385 & $-0,242$ & $-0,221$ & $-0,322$ & 0,541 & 0,826 \\
\hline
\end{tabular}

*valores em negrito e destacados em amarelo representam a raiz quadrada das AVEs

Fonte: Dados da pesquisa

A Tabela 3 apresenta os indicadores de acurácia do modelo ajustado ou validade preditiva $\left(Q^{2}\right)$ e tamanho do efeito ou utilidade para a construção do modelo $\left(f^{2}\right)$ se mostraram satisfatórios. A Sobrecarga de informações apresentou o melhor indicador preditivo no modelo ajustado $\left(f^{2}=0,575\right)$, seguido pela Sobrecarga de papéis com $f^{2}=0,506$. Os 
indicadores de acurácia do modelo foram aceitáveis, com destaque para a Sobrecarga de Informação no vendedor com $\mathrm{Q}^{2}=0,178$.

Tabela 3 - Indicadores de acurácia e utilidade dos construtos

\begin{tabular}{|c|c|c|}
\hline Construto & $\mathbf{Q}^{2}$ & $\mathbf{f}^{2}$ \\
\hline Atitude Policrônica & - & 0,429 \\
\hline Necessidade de Cognição & 0,015 & 0,443 \\
\hline Performance de Vendas & 0,015 & - \\
\hline Satisfação no Trabalho & 0,023 & - \\
\hline $\begin{array}{c}\text { Sobrecarga de Informação do } \\
\text { Vendedor }\end{array}$ & 0,178 & 0,575 \\
\hline Sobrecarga de Papéis & - & 0,506 \\
\hline \multicolumn{2}{|c|}{ Fonte: Dados da pesquisa } \\
\hline
\end{tabular}

Fonte: Dados da pesquisa

Para o teste das hipóteses, utilizou-se o no método de reamostragem bootstrap com 500 subamostras. Foram considerados significativos valores para $\alpha \leq 10 \%$. O modelo proposto explicou 3\% da variância da Performance de vendas, 6\% da Satisfação, 30,5\% da Sobrecarga de Informações no Vendedor e 6,1\% da Necessidade de Cognição. Com relação às relações entre as variáveis, o modelo estrutural não demonstrou relações significantes entre a Atitude Policrônica e a Sobrecarga de Informações no vendedor $\left(\Gamma=-0,0562, \mathrm{t}_{(249)}=1,194\right.$, pvalue $=0.233$ ).

Também não se observou relação significante para o papel mediador da Necessidade de Cognição na relação entre a Atitude Policrônica e a Sobrecarga de Informação no Vendedor (teste de Sobel= -0,564, p-value=0,572), e para a relação entre Sobrecarga de papéis e Sobrecarga de Informações no Vendedor (teste de Sobel= 1,563, p=0,1179).

Observou-se significância na relação entre Sobrecarga de papéis e Sobrecarga de Informações do Vendedor $\left(\Gamma=0,540, \mathrm{t}_{(249)}=7,194, \mathrm{p}<0,001\right)$, entre a Necessidade de cognição e a Sobrecarga de Informações no Vendedor $\left(\Gamma=-0,095, \mathrm{t}_{(249)}=1,719\right.$, $\mathrm{p}$-value=0,086), entre a Sobrecarga de Informações do Vendedor e a Performance de vendas $\left(\Gamma=-0,171, \mathrm{t}_{(249)}=3,007\right.$, p-value $<0,002)$ e entre a Sobrecarga de Informação no Vendedor e a Satisfação no trabalho $\left(\Gamma=-0,245, \mathrm{t}_{(249)}=4,263\right.$, p-value $\left.<0,001\right)$.

Tabela 4 - Resultados do modelo estrutural

\begin{tabular}{|c|l|l|l|c|c|c|c|c|}
\hline $\begin{array}{c}\text { Hipótes } \\
\text { e }\end{array}$ & Sentido & Relacionamento & $\begin{array}{c}\text { Coeficient } \\
\text { e original }\end{array}$ & $\begin{array}{c}\text { Média das } \\
\mathbf{2 4 9} \\
\text { subamostr } \\
\text { as }\end{array}$ & $\begin{array}{c}\text { Erro } \\
\text { padrã } \\
\mathbf{o}\end{array}$ & $\begin{array}{c}\text { Teste } \\
\text { t }\end{array}$ & $\begin{array}{c}\text { p- } \\
\text { value }\end{array}$ & $\begin{array}{c}\text { Resultad } \\
\text { o }\end{array}$ \\
\hline H1a & Negativ & Atitude & $-0,0562$ & $-0,07$ & 0,047 & 1,194 & 0,233 & Rejeitada \\
\hline
\end{tabular}




\begin{tabular}{|c|c|c|c|c|c|c|c|c|}
\hline & o & $\begin{array}{l}\text { Policrônica } \\
\text { Sobrecarga de } \\
\text { informação do } \\
\text { vendedor }\end{array}$ & & & & & & \\
\hline $\mathrm{H} 1 \mathrm{~b}$ & Positivo & $\begin{array}{l}\text { Atitude } \\
\text { Policrônica } \square \square \text { SI } \\
\text { O* Necessidade } \\
\text { de Cognição } \\
\text { (mediação) }\end{array}$ & 0,053 & 0,124 & 0,0892 & $\begin{array}{c}- \\
0,564 \\
*\end{array}$ & $\begin{array}{c}0,572^{*} \\
*\end{array}$ & Rejeitada \\
\hline $\mathrm{H} 2 \mathrm{~b}$ & Positivo & $\begin{array}{l}\text { Sobrecarga de } \\
\text { Papéis } \square \text { SIO* } \\
\text { Necessidade de } \\
\text { Cognição } \\
\text { (mediação) }\end{array}$ & $-0,262$ & $-0,275$ & 0,0748 & $\begin{array}{c}1,563 \\
*\end{array}$ & $\begin{array}{c}0,117 * \\
*\end{array}$ & Rejeitada \\
\hline $\mathrm{H} 2 \mathrm{a}$ & Positivo & $\begin{array}{l}\text { Sobrecarga de } \\
\text { Papéis } \square \\
\text { Sobrecarga de } \\
\text { Informação do } \\
\text { Vendedor }\end{array}$ & 0,54 & 0,536 & 0,0751 & $\begin{array}{c}7,194 \\
1\end{array}$ & 0,001 & Aceita \\
\hline $\mathrm{H} 3$ & $\begin{array}{c}\text { Negativ } \\
0\end{array}$ & $\begin{array}{l}\text { Necessidade de } \\
\text { cognição } \square \\
\text { Sobrecarga de } \\
\text { informação do } \\
\text { vendedor }\end{array}$ & $-0,095$ & $-0,105$ & 0,0554 & 1,719 & 0,086 & $\begin{array}{c}\text { Aceita** } \\
*\end{array}$ \\
\hline $\mathrm{H} 4$ & $\begin{array}{c}\text { Negativ } \\
0\end{array}$ & $\begin{array}{l}\text { Sobrecarga de } \\
\text { informação do } \\
\text { vendedor } \\
\square \text { Performance de } \\
\text { vendas }\end{array}$ & $-0,171$ & $-0,177$ & 0,0571 & 3,007 & 0,002 & Aceita \\
\hline H5 & $\begin{array}{c}\text { Negativ } \\
0\end{array}$ & $\begin{array}{l}\text { Sobrecarga de } \\
\text { informação do } \\
\text { Vendedor } \square \\
\text { Satisfação no } \\
\text { trabalho }\end{array}$ & $-0,245$ & $-0,258$ & 0,0575 & 4,263 & 0,001 & Aceita \\
\hline
\end{tabular}

*Teste Sobel **p-value do teste Sobel $* * * 90 \%$ de confiança

Fonte: Dados da pesquisa

A figura 2 apresenta todos os indicadores do modelo estrutural ajustado final e resume os resultados obtidos por meio da Modelagem de Equações Estruturais: 


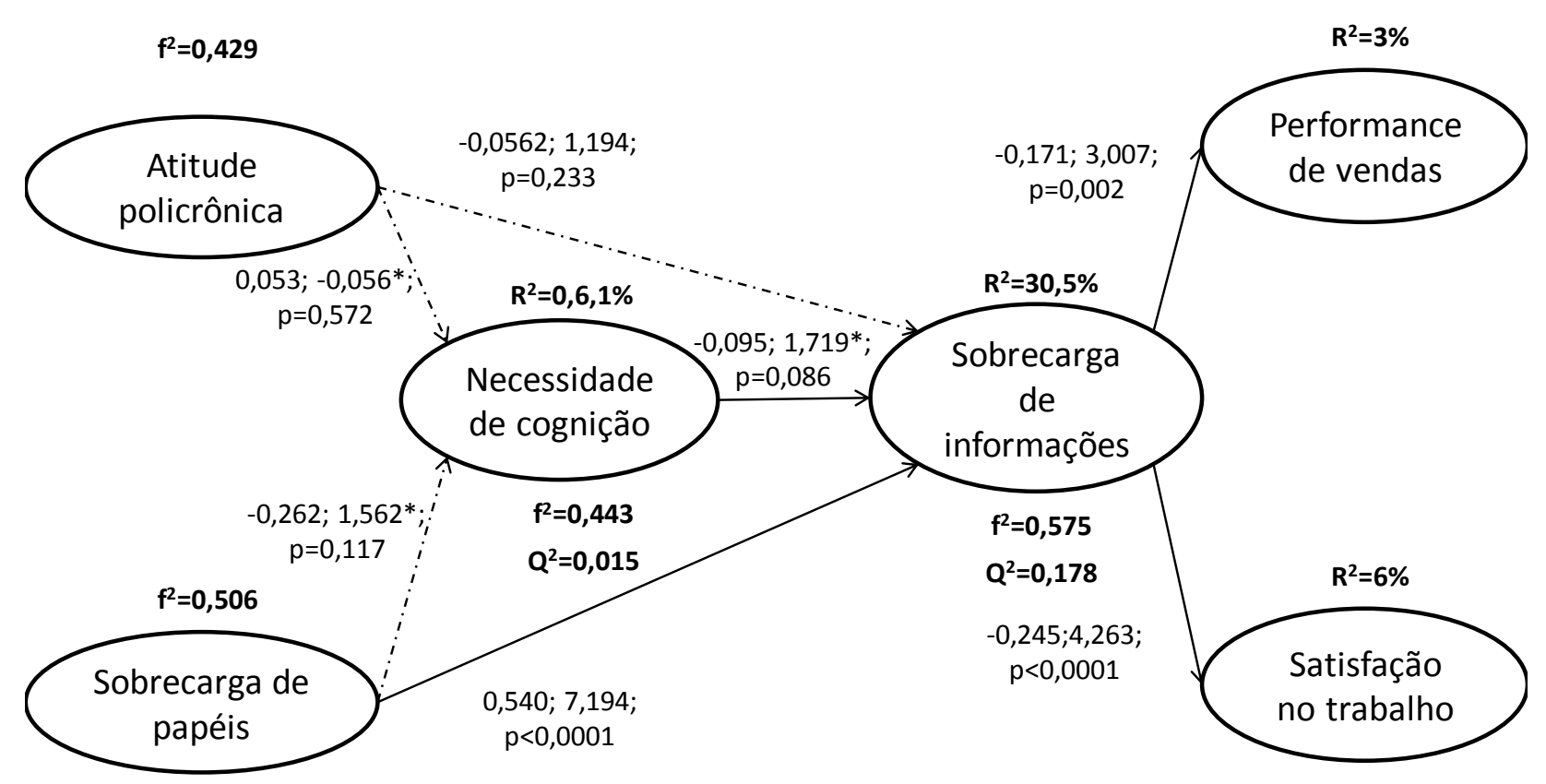

Figura 2 - Indicadores do modelo estrutural final

Fonte: Dados da pesquisa

No próximo capítulo, será apresentada uma discussão dos resultados obtidos com base no modelo teórico proposto.

\section{DISCUSSÃO DOS RESULTADOS}

Em relação ao objetivo geral desta investigação, esta teve a meta de verificar fatores antecedentes e consequentes à Sobrecarga de Informação em Vendedores de lojas físicas de varejo.

Em seus estudos, Hunter e Goebel (2008), não confirmaram a hipótese H1a devido ao baixo efeito $(\beta=-0,121, \mathrm{p}<0,10, \mathrm{t}=-1,684)$. Nesta pesquisa também não foi confirmada a relação entre a Atitude Policrônica e a Sobrecarga de Informação $\left(\Gamma=-0,0562, \mathrm{t}_{(249)}=1,194\right.$, $p$-value $=0,233$ ), ou seja, não se pode afirmar que o vendedor que tenha maior propensão e 
goste mais de fazer mais de uma atividade ao mesmo tempo sofra menos os efeitos da Sobrecarga de Informação. Isso pareceu incompatível com a teoria que atesta que trabalhadores da linha de frente no varejo teriam propensão a emoções mais positivas em seu trabalho caso apresentassem maior Atitude Policrônica, sendo esse o perfil ideal para esse tipo de função devido sua especificidade (ARNDT; ARNOLD; LANDRY, 2006).

A hipótese H1b também não foi confirmada nesta pesquisa (teste de Sobel $=-0,564, p$ = 0,572), ao contrário da pesquisa de Hunter e Goebel (2008), que detectou tal relação. Contudo, deve-se ressaltar que Hunter e Goebel (2008) confirmaram da hipótese sem a apresentação do teste estatístico adequado, como apresentado no presente estudo. Mesmo que nesta nova aplicação o teste de Sobel tenha sido realizado e indicado a não significância da mediação entre os construtos, esse resultado abre portas para novas replicações como forma de investigar essa relação.

A hipótese H2a se confirmou nesta pesquisa $\left(\Gamma=0,540, \mathrm{t}_{(249)}=7,194, \mathrm{p}<0,001\right)$, assim como na pesquisa de Hunter e Goebel (2008). Com isso estão sugeridos, conforme ambas as pesquisas realizadas que, se um vendedor tiver sobrecarga de papéis nas atividades que exerce na sociedade (família, trabalho, religião, etc.), sentirá mais os efeitos da Sobrecarga de Informação. Isso parece compatível com a teoria (REILLY, 1982), já que tais fenômenos são considerados negativos na vida das pessoas, gerando emoções negativas. O excesso de papéis, inclusive, é visto por Ussahawanitchakit (2008) como um fator estressor.

Já a hipótese H2b não se confirmou (teste de Sobel = 1,563, p-value = 0,1179), ocorrendo o contrário do que aconteceu na pesquisa de Hunter e Goebel (2008). Essa não confirmação da mediação da Necessidade de Cognição foi como na relação entre Atitude Policrônica e Sobrecarga de Informação nos Vendedores. Nesta pesquisa, então, conclui-se que o vendedor que tiver Sobrecarga de Papéis sentirá mais os efeitos da Sobrecarga de Informação independentemente de gostar mais de pensar ou não (sem o fator de mediação da Necessidade de Cognição). Entende-se isso pode ser uma das contribuições do estudo, haja vista que no estudo original a relação da mediação da necessidade cognitiva (H3) estava com sentido contrário ao que teoricamente é esperado do construto, como discutido em Cacioppo e Petty (1984).

A hipótese $\mathbf{H 3}$ foi elaborada de maneira contrária ao estudo de Hunter e Goebel (2008). Foi assim eaborada pelo entendimento de que, se o indivíduo gosta muito de pensar, 
por lidar melhor com a informação, sentiria menos os efeitos da Sobrecarga de Informação, gerando uma relação inversamente proporcional. Os resultados observados sugerem a confirmação da hipótese conforme elaborada nesta pesquisa. Mesmo com a significância estatística próxima ao limite crítico $\left(\Gamma=-0,095, \mathrm{t}_{(249)}=1,719\right.$, p-value $\left.=0,086\right)$, não há motivos para sua rejeição.

Analisando os resultados nos testes dos consequentes da Sobrecarga de Informação nos Vendedores, as hipóteses $\mathbf{H 4}\left(\Gamma=-0,171, \mathrm{t}_{(249)}=3,007, p\right.$-value $\left.<0,002\right)$ e $\mathbf{H 5}(\Gamma=-0,245$, $\mathrm{t}_{(249)}=4,263$, $p$-value $\left.<0,001\right)$ foram confirmadas. Este estudo contribuiu na medida em que confirmou os efeitos negativos da Sobrecarga de Informação nos Vendedores na Satisfação no Trabalho e na Performance de vendas.

\section{CONSIDERAÇÕES FINAIS}

O presente estudo cumpriu seu objetivo na medida em que reproduziu os estudos de Hunter e Goebel (2008) acerca da sobrecarga de informação, bem como avançou em aspectos teórico-metodológicos, quando (1) apresenta os resultados a partir do uso de modelagem de equações estruturais e do teste de Sobel, técnicas mais adequadas aos testes das hipóteses propostas no estudo e (2) propõe e confirma a relação negativa entre necessidade de cognição e sobrecarga de informação, diferentemente do estudo original. Sob o primeiro aspecto, nesta pesquisa, os meios para detecção de mediação utilizados foram mais adequados (teste de Sobel) do que os utilizados por Hunter e Goebel (2008), que utilizaram, para demonstração da mediação, duas variáveis independentes, com a Sobrecarga de Informação no Vendedor como dependente. Nos testes, verificaram o $\beta$ (beta) da relação entre os construtos, e indicaram aquele com $\beta$ maior como mediador, contudo tal procedimento pode não indicar mediação.

Este estudo também contribui academicamente na medida em que é uma replicação de um outro, situação esta que colabora positivamente com o desenvolvimento da Ciência. Replicações de trabalhos auxiliam na confirmação (ou não) e na generalização de resultados, e consequentemente na formação de teorias (DANCEY; REIDY, 2006; KERLINGER; 1980; KOÇAK; ABIMBOLA; ÖZER, 2007).

Este estudo pode ser considerado pioneiro no Brasil. Conforme pesquisa realizada em bases de dados de trabalhos científicos como PROQUEST e EBSCO, não foram encontrados registros de publicações a respeito do construto Sobrecarga de Informação em Vendedores 
neste País. O estudo também contribui para o desenvolvimento conceitual do construto, já que há poucas publicações de impacto no mundo científico em geral a respeito de tal fenômeno. Também contribui quando trata de construtos pouco trabalhados na pesquisa científica brasileira, como a Necessidade de Cognição, a Sobrecarga de Papéis e a Atitude Policrônica.

Em relação à pesquisa de Hunter e Goebel (2008), esta pesquisa utilizou uma técnica de análise de dados mais moderna e também uma amostra mais relevante. A modelagem de equações estuturais permite uma análise mais estrita das relações teóricas já que testou todos os construtos pesquisados em conjunto para cálculo do $\mathrm{R}^{2}$, diferentemente de Hunter e Goebel (2008), que utilizaram diversas regressões em seu modelo, testando relação a relação. Quanto a amostra, no estudo original Hunter e Goebel (2008) utilizam uma amostra de 192 vendedores externos de seguros. Ademais, o acesso foi realizado por meio do envio do questionário pelos correios e apenas $24 \%$ dos destinatários retornou os formulários de pesquisa preenchidos.

Mais uma novidade deste estudo foi no teste da relação entre Necessidade de Cognição e Sobrecarga de Informação em Vendedores. Conforme relatado na formulação da hipótese, Hunter e Goebel (2008) testaram verificando se o vendedor com maior Necessidade de Cognição sentiria mais os efeitos da Sobrecarga de Informação por ser alguém que gostasse mais de pensar a respeito das coisas. Entendemos que a formulação dessa hipótese estaria elaborada ao contrário do que diz a teoria. Se o vendedor gosta mais de pensar, este cometeria menos erros e se sentiria menos frustrado com o excesso de informação, diferentemente do que foi proposto e testado por Hunter e Goebel (2008), gerando uma relação inversamente proporcional. A nossa hipótese se confirmou com o vendedor com maior Necessidade de Cognição sentindo menos os efeitos da Sobrecarga de Informação, confirmando a reflexão que havíamos feito a respeito da teoria.

Em relação às implicações gerenciais, é de grande importância para os varejistas entenderem o comportamento e demais situações que afetam seus profissionais no ambiente de trabalho. Conforme demonstrado nos resultados, a Sobrecarga de Informação nos vendedores de lojas físicas de varejo pode reduzir, de certa forma, a satisfação no trabalho desses colaboradores. A Satisfação no Trabalho é de vital importância para as empresas e seus colaboradores, já que, em volume menor, pode aumentar a intenção de turnover (intenção do funcionário de deixar a empresa) (ARNDT; ARNOLD; LANDRY, 2006) e diminuir o comprometimento afetivo com a organização (BOLES; MADUPALLI; RUTHERFORD; 
WOOD, 2007). Já a maior Satisfação no Trabalho pode contribuir para a satisfação do cliente (JEON; CHOI, 2012), e maior comprometimento afetivo e moral do funcionário com a instituição (MACIEL; CAMARGO, 2011).

Em relação aos efeitos da Sobrecarga de Informação nos Vendedores na Performance de Vendas, os resultados indicaram menor desempenho na presença de maior Sobrecarga. Isso seria um problema para as empresas, já que estas dependem diretamente dos resultados desses colaboradores, considerando que são trabalhadores da linha frente, e que representam a organização perante seu principal alvo, que são os clientes (ARNDT; ARNOLD; LANDRY, 2006).

Ações para diminuição da Sobrecarga de Informação podem ser realizadas. Conforme demonstrado nos resultados, o profissional com maior Necessidade de Cognição estaria menos sujeito a esse tipo de efeito. Por isso, empresas do ramo poderiam dar preferência de contratação e promoção a profissionais que tenham esse tipo de perfil, sabendo que isso poderia gerar efeitos positivos nos profissionais quanto a sua satisfação e Performance.

O profissional com Sobrecarga de Papéis também sentiria mais os efeitos da Sobrecarga de Informação. Não parece de praxe empresas do ramo pesquisado darem preferência a profissionais com menos papéis na sociedade (por exemplo, preferência a pessoas com pouca idade e solteiros), podendo isso ser observado na descrição das idades da amostra. Mesmo assim, medidas relacionadas à Gestão de Pessoas podem amenizar os efeitos da Sobrecarga de Papéis. Dentro do próprio trabalho, a quantidade de tarefas poderia ser mais bem distribuída, para que esse profissional não se sinta tão sobrecarregado.

O estudo apresentou algumas limitações. Uma delas foi em relação à amostra, que se limitou a apenas uma classe de vendedores, que foram os vendedores de lojas físicas de varejo de materiais de construção. Estudos futuros poderiam pesquisar vendedores de outros tipos de varejo e também vendedores pessoais. Poderia se pesquisar, também, mais assuntos a respeito de vendedores já que, conforme pesquisas realizadas nas principais bases de dados de artigos científicos (ex. EBSCO e PROQUEST), há certa carência de estudos científicos no Brasil a respeito de vendedores. O estudo com o construto Sobrecarga de Informação nos Vendedores, por exemplo, apareceu como inédito neste País.

Outra limitação desta pesquisa foi a da própria forma de aplicação. Devido a restrições operacionais, conforme já foi citado, não foi permitido que o pesquisador fizesse a aplicação. 
Esta foi feita pelos próprios gerentes das lojas, com entrega de formulários impressos, o que pode ter levado os respondentes a se sentirem receosos de responderem questões diretamente relacionadas ao seu trabalho, inclusive pelo fato deles suspeitarem que poderiam estar sendo identificados.

O fato do questionário ter sido entregue de forma impressa também pode ter sido uma limitação. No planejamento inicial, seria disponibilizado um link eletrônico aos vendedores para que acessassem o questionário. O próprio sistema de aplicação "aleatorizaria" a distribuição das questões, evitando efeitos de ordem de apresentação das variáveis, que seriam aqueles relacionados ao fato de todos os respondentes responderem com a mesma ordem de respostas, minimizando algum tipo de viés de resposta (DANCEY; REIDY, 2006). A forma impressa não gerou questionários randomizados e, sim, uma sequência fixa para todos os respondentes. Estudos futuros poderiam concentrar esforços nos profissionais tendo que acessar algum link em um sistema computacional, fazendo com que o sistema randomizasse as questões. Se a aplicação for por meio de formulário impresso, a preferência seria que este fosse entregue pelo próprio pesquisador, para se aumentar o controle sobre a forma de aplicação, e se diminuir os efeitos da presença do superior imediato. Outra sugestão seria que a Performance fosse captada com os próprios resultados do profissional na verificação de suas vendas e suas avaliações, de forma objetiva, e não com auto declaração, para se evitar efeitos de "desejabilidade social".

O próprio local de aplicação também pode ter sido uma limitação. Os vendedores responderam às questões dentro de seu próprio ambiente e horário de trabalho. Como recebem comissão, podem ter se sentido pressionados a responder de maneira mais acelerada, devido à necessidade de volta ao salão de vendas, podendo, assim, não terem respondido determinadas questões com a devida atenção. Para esse quesito, um estudo futuro poderia ser feito com os vendedores respondendo fora do seu horário de trabalho, para conforto desses profissionais no momento das repostas.

O construto Sobrecarga de Informação em Vendedores está começando a ser explorado no Brasil e com poucas publicações de relevância no mundo. Por esse motivo, esse fenômeno poderia ser melhor explicado ou explicar melhor situações ao ser testado com outros fenômenos. Algumas sugestões seriam verificar a relação do fenômeno com a auto eficácia do vendedor. Hunter e Goebel (2008), por exemplo, sugerem em seus estudos que pesquisas futuras pudessem ser feitas com a auto eficácia mediando a relação entre 
Sobrecarga de Informação nos Vendedores e Performance de Vendas. Também poderia ser verificada a propensão do vendedor à sobrecarga de informação se ele for orientado para vendas ou para o relacionamento. Outra sugestão seria na verificação do processo de Sobrecarga de Informação, no caso do vendedor se utilizar de processos de adaptação aos efeitos (HUNTER; GOEBEL, 2008).

Também como sugestão para futuros estudos, acredita-se que novas replicações devem ser realizadas, principalmente pela não aceitação de parte das hipóteses do estudo original. Nesse contexto, novos testes também poderiam ser efetuados com outros vendedores, de outros tipos de ramo, e se fazer comparações para se verificar os níveis de Sobrecarga de Informação e seus efeitos a cada ramo.

Nota: os autores agradecem pelas excelentes sugestões de melhoria recebidas dos parecistas anônimos da ReAd durante a avaliação das versões iniciais desse trabalho.

\section{Apêndice A - Itens mensurados}

\begin{tabular}{|c|c|}
\hline Dimensão & Assertivas \\
\hline \multirow{6}{*}{$\begin{array}{c}\text { Sobrecarga de } \\
\text { informação nos } \\
\text { vendedores }\end{array}$} & $\begin{array}{l}\text { Eu certamente me sinto frustrado durante uma venda por causa do volume } \\
\text { de informação que eu tenho que apresentar. }\end{array}$ \\
\hline & $\begin{array}{l}\text { A quantidade de informação sobre os produtos que eu tenho que saber para } \\
\text { vender de forma efetiva faz eu me sentir sobrecarregado }\end{array}$ \\
\hline & O volume de informação de vendas que eu tenho que lidar é frustrante. \\
\hline & $\begin{array}{l}\text { O amontoado de informação a respeito de técnicas de vedas que eu tenho } \\
\text { que saber faz eu cometer erros nas apresentações de vendas. }\end{array}$ \\
\hline & $\begin{array}{l}\text { Eu tenho apresentado o produto errado para o cliente errado porque a } \\
\text { quantidade de informação sobre produtos que eu lido é muito grande. }\end{array}$ \\
\hline & $\begin{array}{l}\text { A quantidade de informação que eu tenho que saber a respeito de técnicas } \\
\text { de vendas faz com que eu apresente o produto errado para o cliente errado. }\end{array}$ \\
\hline \multirow{10}{*}{$\begin{array}{c}\text { Atitude } \\
\text { policrônica }\end{array}$} & Eu gosto de lidar com duas ou mais atividades ao mesmo tempo \\
\hline & As pessoas devem tentar fazer mais atividades ao mesmo tempo. \\
\hline & Eu me sinto confortável fazendo duas ou mais atividades ao mesmo tempo \\
\hline & Eu normalmente tento fazer duas ou mais atividades ao mesmo tempo \\
\hline & Eu normalmente faço duas ou mais atividades ao mesmo tempo \\
\hline & Eu me sinto bem fazendo duas ou mais coisas ao mesmo tempo \\
\hline & Eu me sinto energizado quando faço duas ou mais coisas ao mesmo tempo \\
\hline & Eu sou mais eficiente quando faço duas ou mais coisas ao mesmo tempo \\
\hline & Eu sou mais efetivo quando faço duas ou mais coisas ao mesmo tempo \\
\hline & $\begin{array}{l}\text { Eu sinto que as pessoas ao meu redor me aprovam mais quando eu faço } \\
\text { duas ou mais coisas ao mesmo tempo }\end{array}$ \\
\hline
\end{tabular}


Eu tenho que fazer coisas que realmente não tenho tempo e energia para fazê-los

Tem coisas demais que ocupam meu tempo

Eu preciso de mais horas no meu dia para fazer todas as coisas que são esperadas de mim.

Parece que nunca consigo tirar o atraso em minhas atividades

Parece que não tenho tempo para mim mesmo.

Não tenho conseguido atender às expectativas de todo mundo por causa da grande quantidade de atividades que tenho que realizar na minha vida.

Sobrecarga de Às vezes eu sinto como se o dia precisasse de mais horas. papéis

Eu sempre tenho que cancelar compromissos por falta de tempo

Parece que eu tenho que me esticar para conseguir finalizar todas as coisas que eu tenho que fazer.

Parece que eu tenho mais compromissos para cobrir do que outros colegas que eu conheço.

(*)Eu me encontro tendo que preparar listas de prioridades para deixar feitas todas as coisas que eu tenho que fazer. Se eu não fizer isso, eu esqueço, porque tenho muita coisa para fazer.

(*)Eu sinto que acabo fazendo coisas de qualquer jeito, talvez com menor cuidado, pra eu conseguir deixar todas as coisas feitas.

Eu não consigo achar energia em mim para fazer todas as coisas que são esperadas que eu faça.

Eu prefiro mais problemas complexos do que simples.

Eu gosto de ter a responsabilidade de lidar com situações que requerem pensar muito.

Pensar, para mim, é a minha ideia de diversão.

Eu prefiro fazer alguma coisa que exija que eu pense muito e que desafie minhas habilidades de pensar, do que alguma coisa que faça eu pensar pouco.

Eu não evito situações nas quais há a possibilidade de eu ter que pensar profundamente a respeito de alguma coisa.

Eu aprecio ficar pensando profundamente e durante um longo tempo.

Eu penso sobre as coisas muito mais do que eu deveria.

Necessidade cognitiva

Eu prefiro pensar em projetos de longo prazo do que sobre projetos pequenas e que sejam relacionados ao dia a dia.

Eu gosto de tarefas que exigem pensar bastante, mesmo que eu já as tenha aprendido.

Eu realmente aprecio tarefas que envolvam a oportunidade de novas soluções para problemas.

Aprender novas maneiras de pensar sobre as coisas me empolga muito. Eu prefiro minha vida preenchida com quebra-cabeças que eu tenha que resolver.

A noção de pensar abstratamente é o máximo para mim,

Eu prefiro tarefas que sejam intelectuais, difíceis e importantes, do que aquelas que não exijam pensar muito.

Eu me sinto satisfeito depois de completar uma tarefa que exija muito esforço mental. 


\begin{tabular}{|c|c|}
\hline & $\begin{array}{l}\text { Eu me preocupo e me importo muito em saber como e porque as coisas } \\
\text { funcionam. }\end{array}$ \\
\hline & $\begin{array}{l}\text { Eu normalmente me pego deliberando sobre problemas, mesmo que eles } \\
\text { não me afetem. }\end{array}$ \\
\hline \multirow{12}{*}{$\begin{array}{l}\text { Satisfação no } \\
\text { trabalho }\end{array}$} & $\begin{array}{l}\text { Minhas oportunidades de crescimento na empresa em que trabalho são } \\
\text { boas. }\end{array}$ \\
\hline & O ambiente de trabalho é muito bom na empresa em que trabalho. \\
\hline & Considero o meu chefe uma pessoa amigável. \\
\hline & Meu chefe sabe ser líder. \\
\hline & Eu sinto orgulho de trabalhar na empresa em que trabalho. \\
\hline & Eu realmente faço coisas que valem a pena no meu trabalho. \\
\hline & Na empresa em que trabalho são pessoas amigáveis. \\
\hline & $\begin{array}{l}\text { (*) Meu chefe sempre ouve nossas ideias. Meu chefe é uma pessoa que } \\
\text { sempre dá um feedback (retorno) quando preciso. }\end{array}$ \\
\hline & Meu chefe é uma pessoa que cumpre o que promete \\
\hline & Eu sinto prazer em fazer o meu trabalho. \\
\hline & Meus colegas de trabalho são verdadeiros parceiros (companheiros) \\
\hline & $\begin{array}{l}\text { (*) Na empresa em que trabalho, a remuneração e as comissões são } \\
\text { melhores do que em outros lugares para pessoas que fazem a mesma } \\
\text { função que eu. }\end{array}$ \\
\hline \multirow{9}{*}{ Performance } & $\begin{array}{l}\text { Que nota eu dou para mim mesmo no quanto tenho contribuído no alcance } \\
\text { das metas do meu gerente? }\end{array}$ \\
\hline & $\begin{array}{l}\text { Que nota eu dou para mim mesmo na posição em vendas (R\$) que ocupo } \\
\text { em relação aos meus colegas? }\end{array}$ \\
\hline & $\begin{array}{l}\text { Que nota eu dou para mim mesmo no ganho de comissões em relação aos } \\
\text { meus colegas? }\end{array}$ \\
\hline & $\begin{array}{l}\text { Que nota eu dou para mim mesmo no quanto tenho contribuído no alcance } \\
\text { das metas de vendas da loja? }\end{array}$ \\
\hline & $\begin{array}{l}\text { Que nota eu dou para mim mesmo no quanto tenho contribuído no alcance } \\
\text { das metas de vendas do meu setor? }\end{array}$ \\
\hline & $\begin{array}{l}\text { Que nota eu dou para mim mesmo no quanto tenho vendido de produtos } \\
\text { que me gerem mais comissão? }\end{array}$ \\
\hline & $\begin{array}{l}\text { Que nota eu dou para mim mesmo no quanto tenho alcançado metas e } \\
\text { quotas de vendas? }\end{array}$ \\
\hline & Que nota eu dou para mim mesmo na venda de novos produtos? \\
\hline & $\begin{array}{l}\text { Que nota eu dou para mim mesmo para o meu volume de vendas em reais } \\
(\mathrm{R} \$) \text { ? }\end{array}$ \\
\hline
\end{tabular}

(*) Itens eliminados durante a análise dos dados

\section{REFERÊNCIAS}

ABEP - Associação Brasileira de Empresas de Pesquisa. 2014. Disponível em: <file:///C:/Users/Enos/Downloads/09_cceb_2014.pdf>. Acesso em: 14 ago. 2014. 
ANAMACO - Associação Nacional de Comerciantes de Materiais de Construção. 2013. Disponível em: <http://novo.anamaco.com.br/dadosSetor-interna. aspx?uid=9>. Acesso em: 22 dez. 2013.

ARNDT, A.; ARNOLD, T. J.; LANDRY, T. D. The effects of polychronic-orientation upon retail employee satisfaction and turnover. Journal of Retailing, Greenwich, v. 82, n. 4, p. 319-330, 2006.

BOLES, J. et al. The relationship of facets of Salespersons' job satisfaction with affective organizational commitment. The Journal of Business \& Industrial Marketing, Santa Barbara, v. 22, n. 5, p. 311-321, 2007.

CACIOPPO, J. T.; PETTY, R. E. The Need for Cognition. Journal of Personality and Social Psychology, Washington, v. 42, n. 1, p. 116-131, Jan. 1982.

CACIOPPO, J. T.; PETTY, R. E.; KAO, C. F. The efficient assessment of Need for Cognition. Journal of Personality Assesment, v. 48, n. 3, p. 306-307, 1984.

CHIN, W. W. The partial least squares approach for structural equation modeling. In MARCOULIDES, G.A. (Ed.). Modern methods for business research. London: Lawrence Erlbaum Associates, 1998. p. 295-236.

COOPER, D. R.; SCHINDLER, P. S. Métodos de Pesquisa em Administração. 7. ed. São Paulo: Ed. Bookman, 2007.

COHEN, J. Statistical Power Analysis for the Behavioral Sciences. 2. ed. New York: Psychology Press, 1988.

CROWNE, D. P.; Marlowe, D. A new scale of social desirability independent of psychopathology. Journal Of Consulting Psychology, Worcester, v. 24, p. 349-354, 1960.

DANCEY, C. P.; REIDY, J. N. Estatística sem matemática para Psicologia. 3. ed. Porto Alegre: Artmed Bookman, 2006.

DELPECHITRE, D. Review and assessment of past empathy scales to measure Salespersons's empathy. Journal Of Management \& Marketing Research, [s.1.], v. 13, p. $1-16,2013$.

FLYNN, L.; PEARCY, D. Four subtle sins in scale development: some suggestions for strengthening the current paradigm. International Journal Of Market Research, [s.1.], v. 43, p. 409-423, 2001.

GAUR, S. S.; YAP, S. F.; HAN, D. Relationship selling behavior's impact on sales performance: The moderating role of Salesperson's Information Overload. AMA Summer Educators' Conference Proceedings, Chicago, v. 24, p. 66-67, Jan. 2013.

GUO, L.; IRENE C.L. The antecedents of salespeople's relational behaviors. The Journal of Business \& Industrial Marketing, Santa Barbara, v. 27, n. 5, p. 412-419, 2012.

HAIR, J. F. et al. Análise multivariada de dados. 6. ed. Porto Alegre: Bookman, 2010. 
HAIR, J. F. et al. A Primer on Partial Least Squares Structural Equation Modeling (PLS-SEM). Los Angeles: SAGE, 2014.

HUNT, J. M. et al. Socially Desirable in the Measurement of Need for Cognition. Advances in Consumer Research, [s.1.], v. 21, p. 543-546, 1994.

HUNTER, G. L. Information Overload: Guidance for Identifying When Information Becomes Detrimental to Sales Force Performance. Journal of Personal Selling \& Sales, Abingdon, v. 24, n. 2, p. 91-100, 2004.

HUNTER, G. L.; GOEBEL, D. J. Salesperson's Information Overload: Scale Development, Validation, and its Relationship to Salespersons' job satisfaction and performance. Journal of Personal Selling and Sales Management, Abingdon, v. 28, n. 1, p. 21-35, winter 2008.

JACOBY, J.; SPELLER, D. E.; ET, A. Brand choice behavior as a function of information load - Replication and extension. Journal of Consumer Research, Chicago, v. 1, n. 1, p. 33, JUNE 1974.

JEON, H.; CHOI, B. The relationship between employee satisfaction and customer satisfaction. The Journal of Services Marketing, Santa Barbara, v. 26, n. 5, p. 332-341, 2012.

KAUFMAN, C. F.; LANE, P. M.; LINDQUIST, J. D. Exploring More Than 24 Hours a Day: A Preliminary Investigation of Polychronic Time Use. Journal of Consumer Research, Gainesville, v. 18, n. 3, p. 392, 1991.

KERLINGER, F. N. Metodologia da pesquisa em Ciências Sociais: um tratamento conceitual. São Paulo: EPU, 1980.

KIM, J.; KIM, J. Human factors in retail environments: a review. International Journal of Retail \& Distribution Management, Bingley, v. 40, p. 818-841, 2012.

KOÇAK, A.; ABIMBOLA, T.; ÖZER, A. Consumer Brand Equity in a Cross-cultural Replication: An Evaluation of a Scale. Journal of Marketing Management, Hoboken, v. 23 n. 1/2, p. 157-173, 2007.

LINDQUIST, J.D.; KAUFMAN-SCARBOROUGH, C. The Polychronic-Monochronic Tendency Model. PMTS scale development and validation. Time \& Society, Thousand Oaks, v. 16, n. 2-3, p. 253-285, sept. 2007.

LU, L.; LEE, Y. The effects of supervision style and decision-making on role stress and satisfaction of senior foreign managers in international joint ventures in China. International Journal of Commerce and Management, Bingley, v. 17, n. 4, p. 284-294, 2007.

MACIEL, C.D.O.; CAMARGO, C. Comprometimento, Satisfação e Cooperação no Trabalho: Evidências da Primazia dos Aspectos Morais e das Normas de Reciprocidade Sobre o Comportamento. Revista de Administração Contemporânea, Rio de Janeiro, v. 15, n. 3, p. 433-453, maio 2011. 
MALHOTRA, N. K. Pesquisa de marketing: uma orientação aplicada. 3. ed. Porto Alegre: Ed. Bookman, 2004.

MALHOTRA, N. K. Marketing Research: An Applied Orientation. 6. Ed. Georgia: Ed. Pearson, 2009.

MALHOTRA, N. K.; LOPES, E.L.; Veiga, R.T. Modelagem de Equações Estruturais com Lisrel: Uma Visão Inicial. REMark, São Paulo, v. 13, n. 2, p. 27, 2014.

MILLER, George. The Magical Number Seven, Plus or Minus Two: Some Limits on Our Capacity for Processing Information. Psychological Review, Amsterdam, v. 63, p. 81-97, mar. 1956.

NONIS, S. A.; ERDEM, S. A. A Refinement of Indsales to Measure Job Satisfaction Of Sales Personnel in General Marketing Settings. Journal Of Marketing Management, Abingdon, v. 7, p. 34-46, 1997.

PARENTE, J.; BURKI, E. Varejo no Brasil: gestão e estratégia. 2. ed. São Paulo: Atlas, 2000.

REILLY, M. D. Working Wives and Convenience Consumption. Journal of Consumer Research, Gainesville, v. 8, n. 4, p. 407-418, feb. 1982.

RINGLE, C. M.; SILVA, D.; BIDO, D. S. Modelagem de Equações Estruturais com Utilização do Smartpls. REMark, São Paulo, v. 13, n. 2, p. 54, 2014.

SLOCOMBE, T. E.; BLUEDORN, A. C. Organizational behavior implications of the congruence between preferred polychronicity and experienced work-unit polychronicity. Journal of Organizational Behavior, Chichester, v. 20, n. 1, p. 75-99, jan. 1999.

SANTANA, S; CERDEIRA, J. Satisfação no trabalho dos profissionais do ACeS Baixo Vouga 1l. ActaMedica Portuguesa, [s.1.], v. 24, p. 589-600, 2011.

SINGH, J. Performance productivity and quality of frontline employees in service organizations. Journal of Marketing, Chicago, v. 64, n. 2, p. 15-34, apr. 2000.

SINGH, R.; KOSHY, A. Determinants of B2B Salesperson's performance and effectiveness: a review and synthesis of literature. The Journal of Business \& Industrial Marketing, Santa Barbara, v. 25, n. 7, p. 535-546, 2010.

SUJAN, H.; WEITZ, B.A.; KUMAR, N. Learning, orientation, working smart, and effective selling. Journal of Marketing, Chicago, v. 58, n. 3, p. 39-52, july 1994.

TENENHAUS, M. et al. PLS Path Modeling. Computational Statistics \& Data Analysis, Amsterdam, v. 48, p. 159-205, 2005.

TURLEY, L.W.; MILLIMAN R. E. Atmospheric effects on shopping behavior: a review of the experimental evidence. Journal of Business Research, Amsterdam, v. 49, p. 193-211, 2000 . 
USSAHAWANITCHAKIT, P. Building job satisfaction of certified public accounts (CPAs) in Thailand: Effects of role stress through role conflict, role ambiguity and role overload. Journal Of The Academy Of Business \& Economics,[s.1.] v. 8, p.12-22, 20 mar. 2008.

WETZELS, M.; ODEKERKEN-SCHRÖDER, G.; OPPEN, C.V. Using PLS path modeling for assessing hierarchical construct models: guidelines and empirical illustration. MIS Quarterly, Minneapolis, v. 33, n. 1, p. 177-195, mar. 2009.

ZALLOCCO, R.; ELLEN, B.P.; MALLIN, M.L. A re-examination of B2B sales performance. The Journal of Business \& Industrial Marketing, Santa Barbara, v. 24, n. 8, p. 598-610, 2009. 